\title{
DESENVOLVIMENTO DE UM SISTEMA DE ABASTECIMENTO DE ÁGUA AUTOMATIZADO PARA FINS DIDÁTICOS MULTIDISCIPLINAR
}

Heuler Andrade Silva - heuler.andrades@gmail.com

Gabriel Gomes Oliveira Melo - gabrielgomes2597@gmail.com

Gustavo Lobato Campos - gustavo.lobato@ifmg.edu.br

Ana Paula Lima dos Santos-anapaula.lima@ifmg.edu.br

Instituto Federal de Educação, Ciência e Tecnologia de Minas Gerais Campus Formiga

Rua Padre Alberico, 440 - Bairro São Luiz

35577-010 - Formiga - Minas Gerais

Resumo: A busca por sistemas auxiliares de ensino tem se tornado importante para o desenvolvimento dos alunos, principalmente quando esses métodos são relacionadas ou implicam na reprodução em escala reduzida de um processo industrial, tudo para garantir que o aluno possa colocar em prática o conteúdo aprendido em disciplinas, contribuindo para seu acesso ao mercado de trabalho que se torna cada vez mais exigente. Desse modo, um processo com aplicações distintas, além de sua alta empregabilidade no setor industrial, é o gerenciamento de recursos hídricos, processo ao qual são relacionadas diversas técnicas de sensoriamento e atuação, o que ressalta a importância de seu entendimento por parte dos alunos, seja pela compreensão do próprio processo ou até mesmo pelo conhecimento em aquisição de sinais de campo, processamento desses sinais, armazenamento e disposição em uma interface de alto nível (SCADA). Assim, o presente artigo descreve o desenvolvimento de um protótipo do sistema de distribuição de uma estação de tratamento de água (ETA) em escala reduzida, cujo diferencial é o emprego da interdisciplinaridade para seu desenvolvimento com destaque por exemplo para áreas como sistemas embarcados, automação, instrumentação, lógica e programação, com especial atenção para o sistema supervisório. Tudo isso a fim de apresentar aos discentes do Instituto Federal de Educação, Ciência e Tecnologia de Minas Gerais, Campus Formiga, um desafio similar ao que pode ser encontrado na atuação profissional como engenheiros, ressaltando a importância da prática de conceitos teóricos aprendidos.

Palavras-chave: Interdisciplinaridade. Automação. Sistema embarcado. Estação de tratamento de água. 


\section{INTRODUÇÃO}

O conceito de didática tem por fim possibilitar e facilitar a aprendizagem, visando ensinar técnicas e orientar atividades educativas (GERONIMO, 2017). Observa-se cada vez mais que as universidades têm buscado soluções inovadoras, a fim de disponibilizar uma didática que possibilite ao aluno uma prática maior, colocando-o em contato com ambientes que simulam aqueles encontrados na indústria. Nesse sentido, em busca de proporcionar ao aluno um ambiente similar ao encontrado no setor industrial é que estudos na área de desenvolvimento e construção, por exemplo, de bancadas didáticas vêm sendo discutidos e apresentados na literatura com o teor de proporcionar esse estreitamento entre teoria e prática (DOS SANTOS; MACHADO; DE SOUZA, 2018), muitas vezes com o objetivo de apresentar um determinado sistema em escala reduzida.

$\mathrm{Na}$ área de engenharia elétrica, destacam-se por exemplo as áreas de eletrônica e automação industrial, nas quais é fundamental o conhecimento por parte do aluno sobre o funcionamento de sensores, atuadores, controlador, além do tipo de sinal utilizado, seja de entrada ou saída, podendo ainda se de natureza analógica ou digital. Neste contexto, o processo de controle hídrico possui uma grande capacidade didática, pois, além de sua forte empregabilidade por parte do setor industrial e das estações de tratamento de água (ETA), traz consigo valores de conscientização e meio ambiente.

A automação das estações de tratamento de água pode amenizar problemas como a baixa disponibilidade, vazamentos, imprecisão e fraudes, fatores estes que levou a prejuízos de $38,7 \%$ no cenário nacional em 2017, isto em ordem financeira de 10 bilhões de reais segundo o Sistema Nacional de Informações sobre Saneamento (SINIS, 2017). Contudo não somente o aspecto financeiro demonstra a relevância deste tipo de solução, visto que a automação desse sistema traz consigo valores ambientais com melhor controle desse recurso que define aspectos fundamentais de civilização humana, o que o torna parte dos 17 "Objetivos de Desenvolvimento Sustentável (ODS), que são metas globais regidas na Resolução 70/1 da Assembleia Geral das Nações Unidas (UNITED NATIONS, 2016).

Desse modo, o objetivo desse trabalho é o desenvolvimento de um sistema protótipo em escala reduzida, passível de ser aplicado como uma bancada didática para ensino que aborde conteúdos multidisciplinares, como por exemplo, aqueles relacionados com: sistemas embarcados; eletrônica; automação; instrumentação; lógica e programação, com especial atenção para o sistema supervisório. Trata-se especificamente de um sistema protótipo que permita estabelecer uma automação para um sistema de gerenciamento hídrico, nesse caso simulando um processo de uma estação de tratamento de água (ETA).

\section{ESTAÇÃO DE TRATAMENTO DE ÁGUA}

As estações de tratamento de água (ETA) são instalações que realizam a purificação da água captada de alguma fonte para torná-la própria para o consumo e assim utilizá-la para abastecer a população. A agua é então captada em rio e passa por um processo de tratamento em que é armazenada em um reservatório principal e só então é distribuída em reservatório secundários, localizados conforme opções estratégicas definidas pela concessionária.

Contudo observa-se em grande parte das cidades do interior do Brasil que a gestão deste sistema ainda se faz de forma manual, com leituras de níveis e controle de válvulas sendo realizadas por funcionários do sistema de abastecimento da autarquia local. Nesse contexto verifica-se uma lacuna relacionada ao sistema de distribuição hídrico. Quanto à finalidade dos reservatórios, o Decreto Regulamentar no 23/95 de 1995, define, no seu artigo $67^{\circ}$ que: 
"Os reservatórios têm principalmente as seguintes finalidades:

a) Servir de volante de regularização, compensando as flutuações de consumo face à adução;

b) Constituir reservas de emergência para combate a incêndios ou para assegurar a distribuição em casos de interrupção voluntária

ou acidental do sistema de montante;

c) Equilibrar as pressões na rede de distribuição;

d) Regularizar o funcionamento das bombas".

Na sua maioria, os reservatórios têm funções de volantes de regularização, alimentando diretamente as redes de distribuição de água e permitindo compensar as flutuações do consumo face a um regime constante ou intermitente do sistema de adução. Por vezes, a alimentação de uma rede é feita, nos períodos de ponta de consumo, a partir de dois reservatórios, o principal no final da adução e o outro de extremidade, a cota inferior à do primeiro e alimentado através da rede nos períodos de fraco ou nulo consumo.

Sendo assim, a fim de proporcionar um estudo aprimorado e implementar testes, é proposto o desenvolvimento de um sistema protótipo em escala reduzida de uma plataforma de distribuição, conforme representado na Figura 1, na qual observa-se o sistema com um tanque principal e dois tanques secundários.

Figura 1 - Representação do sistema em CAD.

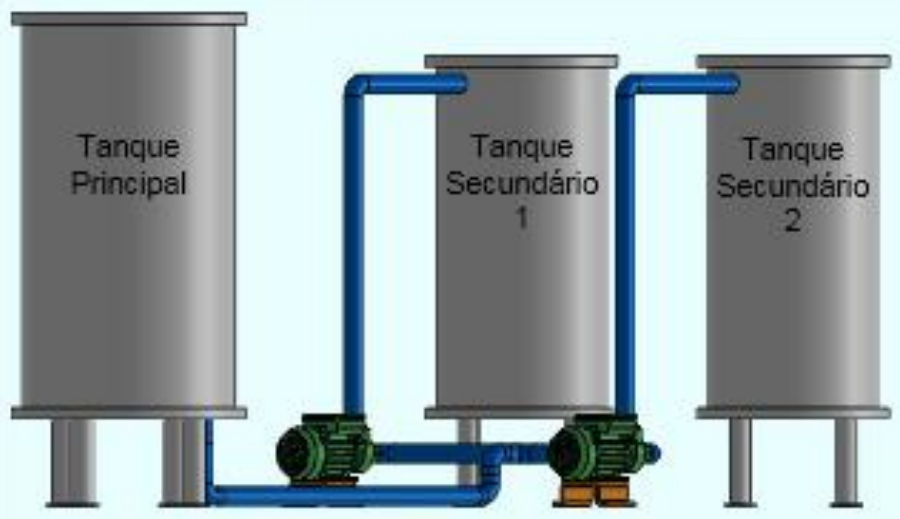

Fonte: Autoria Própria.

\section{DESENVOLVIMENTO}

Para confecção do protótipo foram utilizados tubos de PVC de 50mm, para representar os tanques, sendo que o tanque principal possui altura de $40 \mathrm{~cm}$, enquanto que os secundários possuem altura de $30 \mathrm{~cm}$. Para a conexão entre os reservatórios e as bombas, foram utilizados mangueiras e conexões de 1/2". As bombas empregadas no protótipo são reutilizadas do sistema de para-brisa veicular e possuem alimentação em $12 \mathrm{~V}$. Para execução das mesmas foi necessário a utilização de módulos relés de $5 \mathrm{~V}$.

Foram utilizados dois sensores bluetooth HC-05 com alcance de até 10 metros, um dos módulos foi configurado para funcionar como modo slave (apenas envia o sinal dos níveis) e o outro módulo foi configurado para funcionar como modo master (recebe o sinal e realiza um tratamento e execução com base no mesmo). A representação do circuito segue na Figura 2 onde é possível identificar a ligação de sensores e atuadores nas plataformas Arduino, apresentando o sistema de comunicação master e slave. 
(C) COBENGE

"Os desafios para formar hoje o engenheiro do amanhã"
O1 a 03 de dezembro

Evento On-line

Figura 2 - Esquemático de conexão dos componentes.
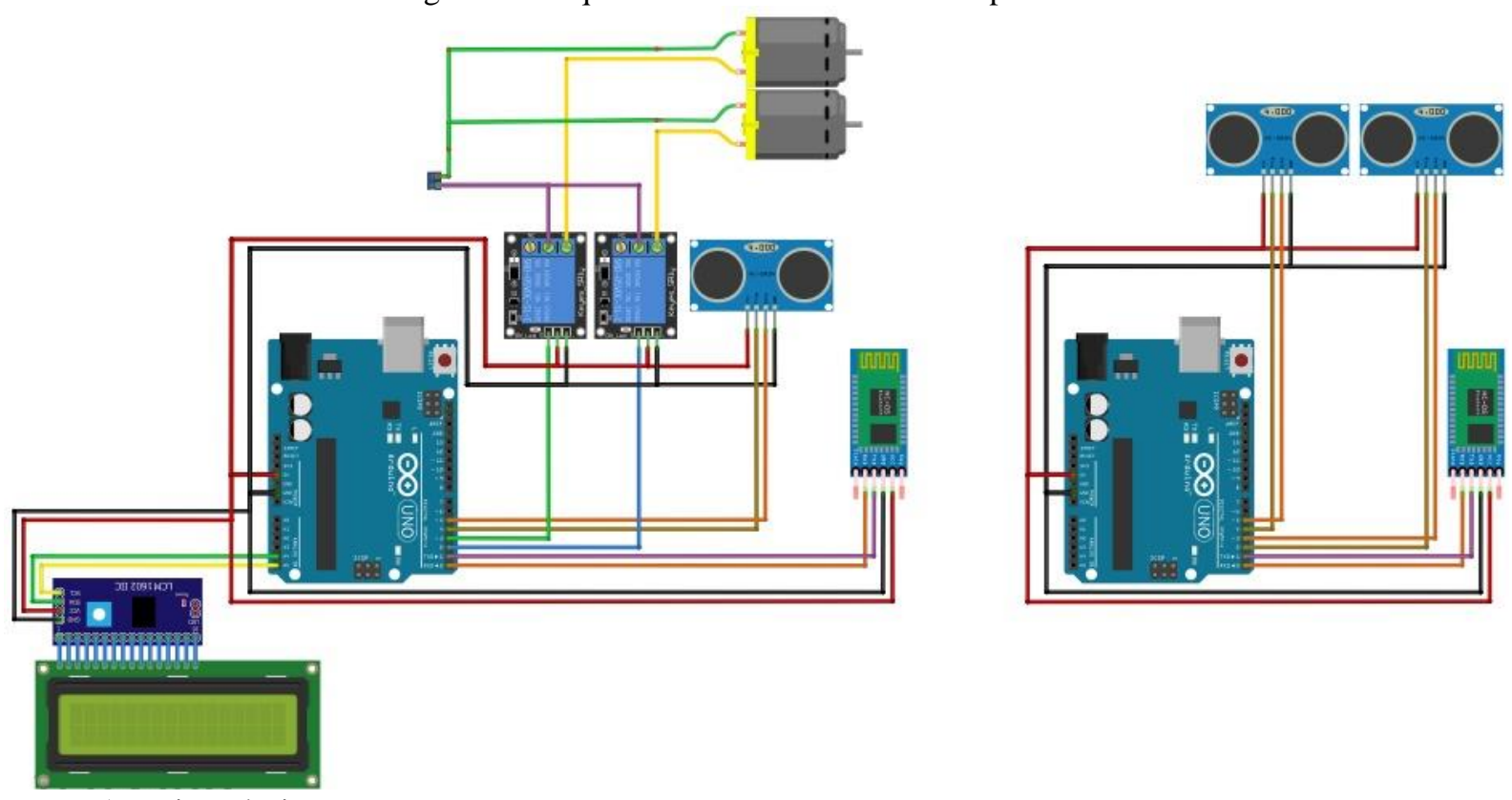

Fonte: Autoria Própria.

O trabalho ainda resultou no desenvolvimento de placas de circuito impresso (PCB) dedicadas para acoplagem das plataformas Arduino apresentadas na Figura 3, tanto às PCBs do circuito mestre quanto escravo.

Figura 3 - Esquemático das placas de circuito impresso.
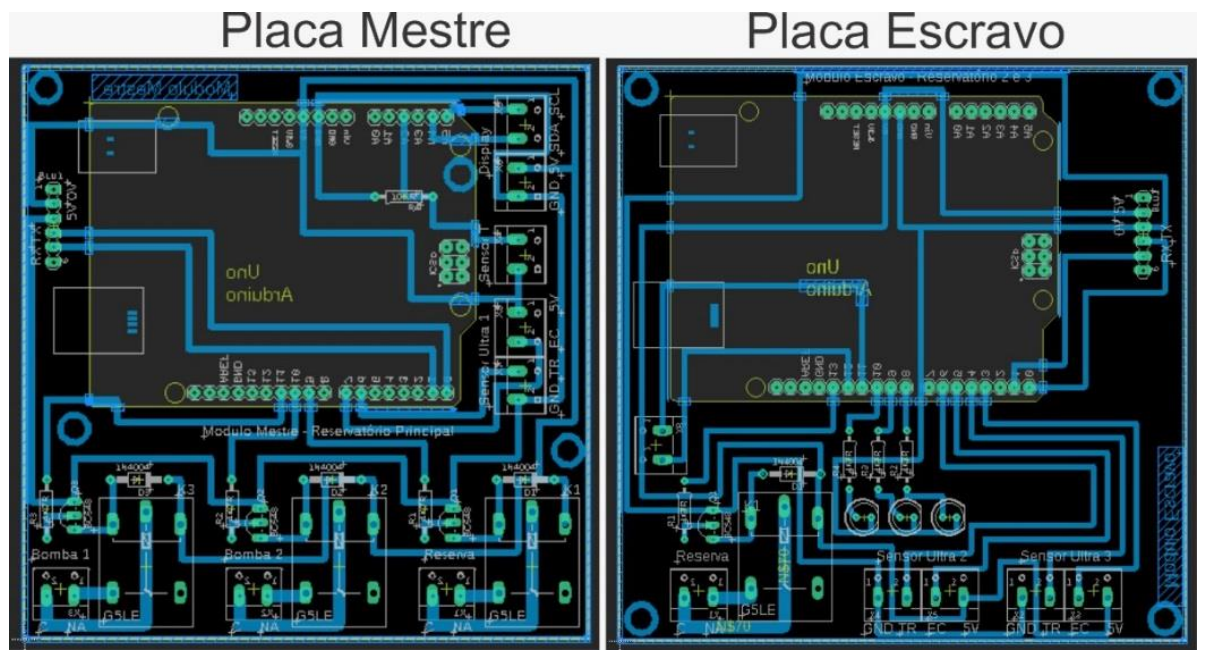

Fonte: Autoria Própria.

Adicionalmente, foi objeto de trabalho o desenvolvimento de um sistema supervisório, para o qual foi utilizado software Elipse E3. As informações coletadas são transmitidas, manipuladas, observadas, analisadas, conservadas e, finalmente, apresentadas ao operador em multiplicidade de formas, por meio de uma interface de alto nível (COMER, 2016).

O Elipse E3 foi executado em modo de demonstração, sendo que este o permite ser executado por um tempo de até 2 horas, para cada vez que é executado, e ainda habilita o uso de no máximo 20 tags de comunicação, estas necessárias para sincronizar uma variável do supervisório com uma variável da plataforma Arduino. 


\section{RESULTADOS}

Nesta seção são apresentados resultados das etapas de desenvolvimento, assim como o resultado completo do sistema protótipo.

\subsection{SISTEMA MASTER}

$\mathrm{Na}$ Figura 4 (a) apresenta-se o sistema mestre ou "master" com seus componentes principais e já alocados em estrutura confeccionada para o protótipo.

Figura 4 - Sistema mestre, e imagem do display do protótipo do protótipo desenvolvido.

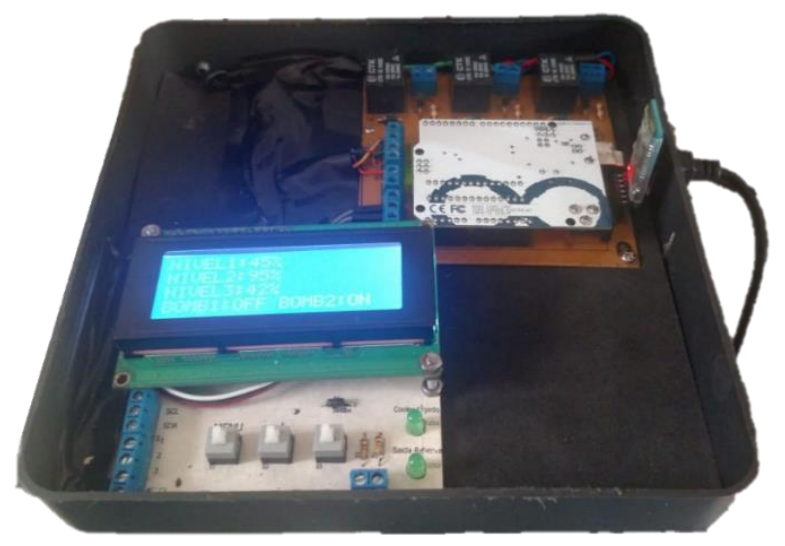

(a)

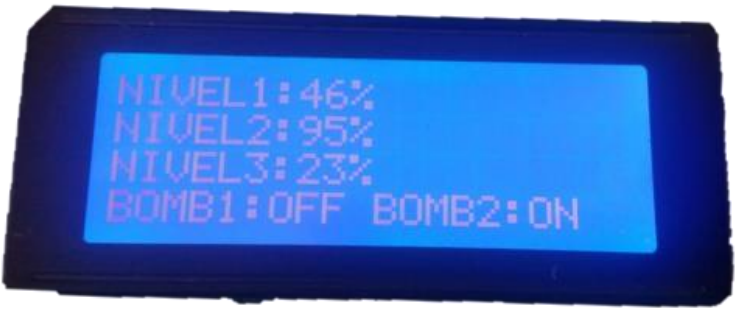

(b)

Fonte: Autoria Própria.

O sistema mestre é composto por um Arduino Uno, relés para acionamentos das bombas, módulo bluetooth HC-05, entrada para ligação do sensor ultrassônico do reservatório principal e um display, onde apresenta-se o nível correspondente a cada um dos três reservatórios, assim como o status de cada uma das duas bombas (se ligadas ou desligadas), conforme pode ser visualizado pela Figura 4 (b). As demais portas do Arduino foram reservadas para futuras expansões e evolução do protótipo.

Pode-se observar que no momento da captura da imagem apresentada na Figura 4 (b) que a bomba correspondente ao reservatório 2 estava acionada. Enfatiza-se aqui que a lógica de comando aplicada ao sistema aciona uma determinada bomba quando o nível do reservatório for inferior a $25 \%$ e desliga a mesma quando o nível chegar a $100 \%$.

\subsection{SISTEMA SLAVE}

O sistema escravo, ou "slave" é apresentado na Figura 5, também já com sua estrutura de alocação. Especificamente o sistema escravo é composto por um Arduino Uno, módulo bluetooth HC-05, entrada para ligação de dois sensores ultrassônicos referentes aos reservatórios secundários e uma bateria de $9 \mathrm{~V}$ para alimentação. As demais portas do Arduino são destinadas à futuras expansões e evolução do protótipo, similar ao previsto para o sistema master. 


\section{COBENCE de Educação em Engenharia da ABENGE}

"Os desafios para formar hoje o engenheiro do amanhã"

Figura 5 - Sistema escravo do protótipo desenvolvido.

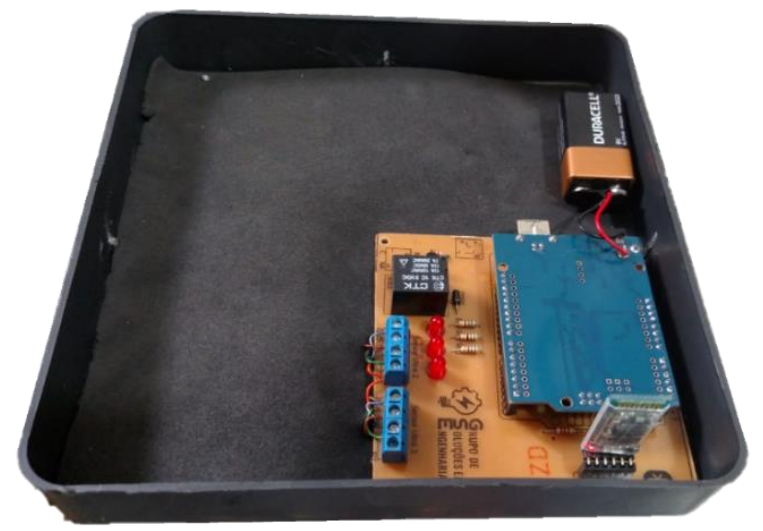

Fonte: Autoria Própria.

\subsection{SUPERVISÓRIO}

O supervisório foi desenvolvido no programa Elipse E3, e este conta com um banco de dados de cadastro de usuários. Desse modo, é possível definir cada funcionalidade que cada usuário pode ter, além de requisitar nome e senha logo após a inicialização do programa. Após efetuar o login, a página inicial vista pelo usuário é a apresentada na Figura 6.

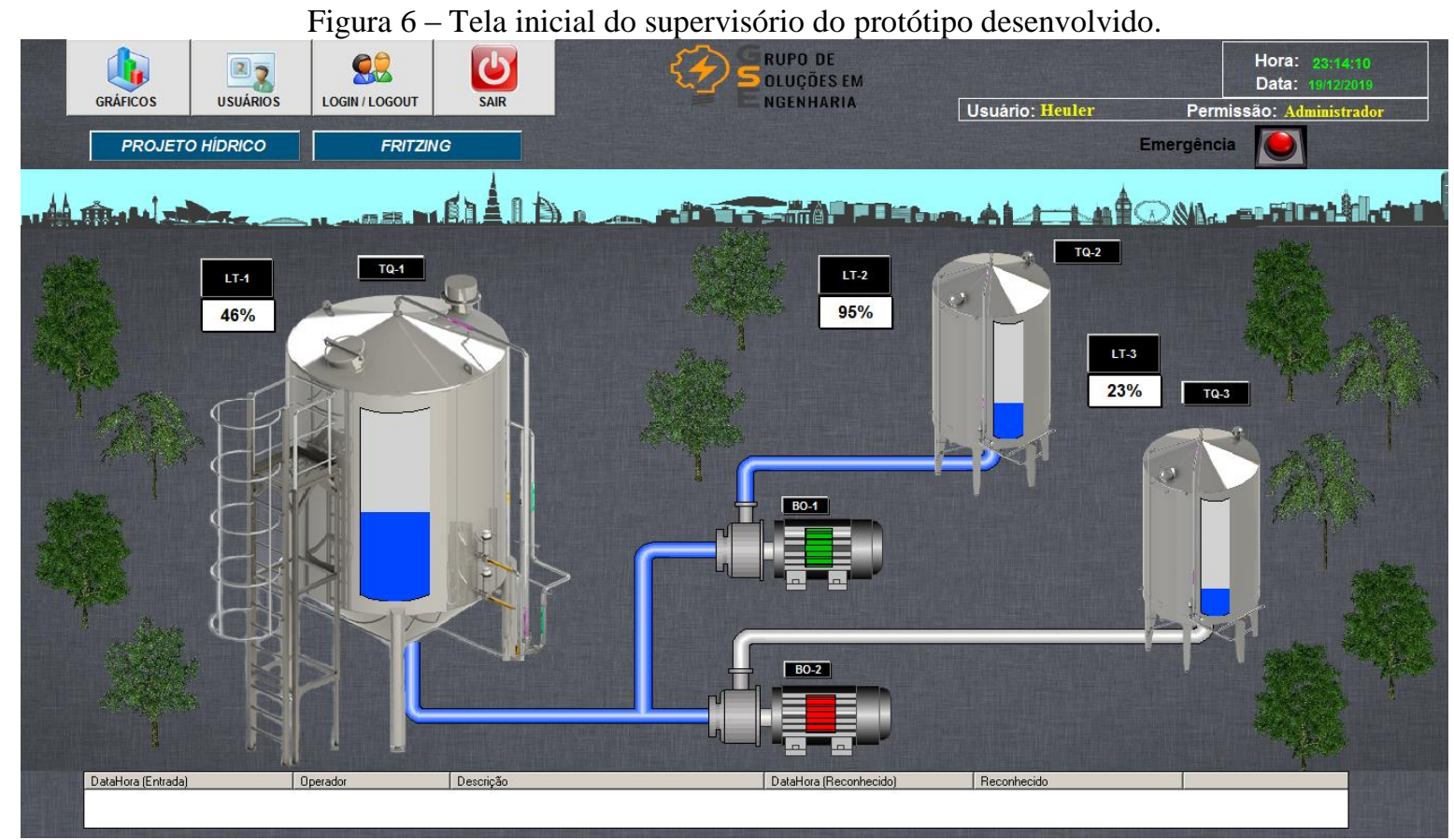

Fonte: Autoria Própria.

Trata-se de interface intuitiva onde é possível visualizar a representação de nível de cada tanque em questão, além do estado de funcionamento de cada bomba que possui uma tonalidade diferente para cada estado (ligado e desligado), além de uma animação indicando quando está ligada. Para visualizar o gráfico de cada tanque ou alterar o estado de funcionamento das bombas, basta clicar sob o item pretendido e uma nova janela minimizada irá abrir. A Figura 7 mostra, em (a) a tela de configuração das bombas (estado de funcionamento e opções de controle manual e automático). Já em (b) tem-se a tela de visualização do nível de cada um dos tanques do sistema. 
Figura 7 - Tela de controle de bombas e visualização de níveis dos tanques do protótipo desenvolvido.

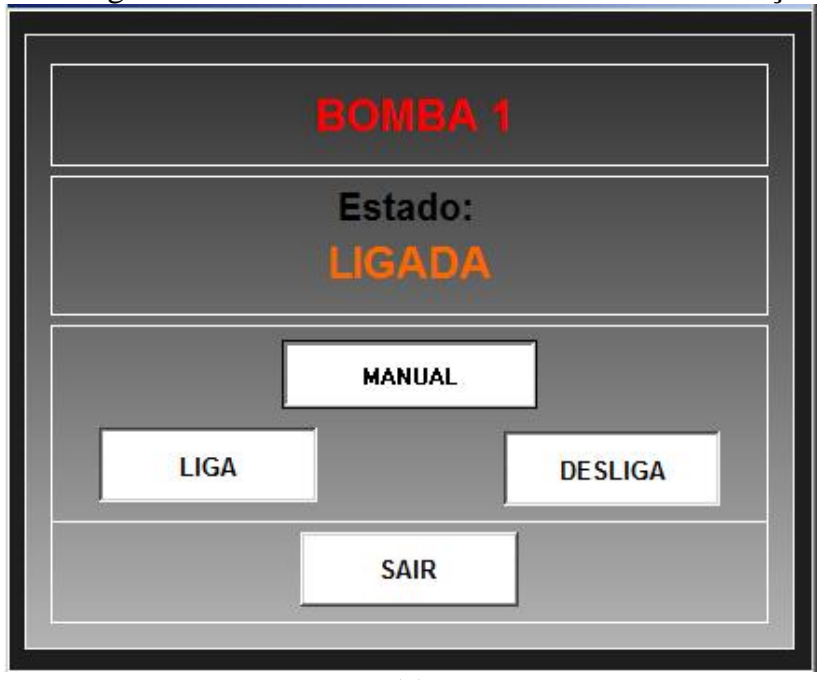

(a)

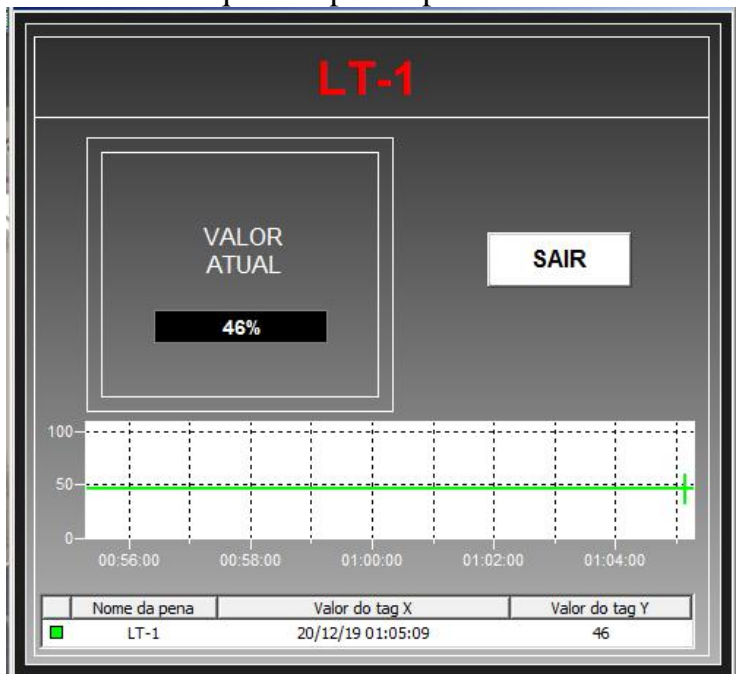

(b)

Fonte: Autoria Própria.

Por meio dos dados obtidos e salvos em um bando de dados, utilizando a guia "Gráficos" é possível realizar consultas de valores de nível conforme um intervalo de tempo escolhido, como mostra a Figura 8.

Figura 8 - Tela de gráficos e consulta ao banco de dados do protótipo desenvolvido.

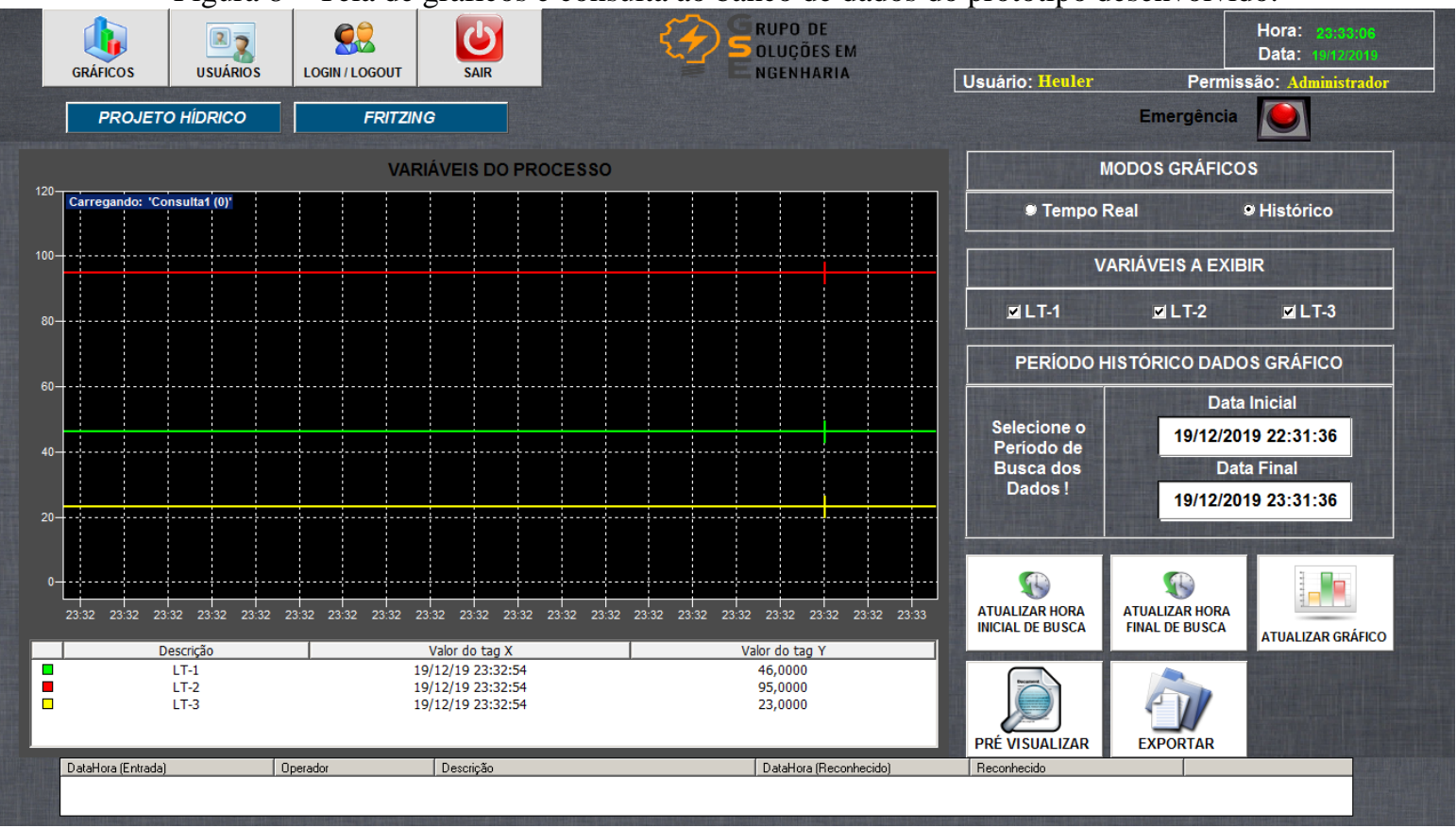

Fonte: Autoria Própria.

Ainda, é possível gerar um arquivo em formato PDF com os dados selecionados, assim como existe a possibilidade de se exportar os dados do banco para um arquivo em formato XLSX. 


\subsection{O PROTÓTIPO}

O protótipo final é apresentado na Figura 9, onde é realizada a sincronização de todo o sistema, incluindo sensores, atuadores, comunicação sem fio, lógica de controle e supervisório.

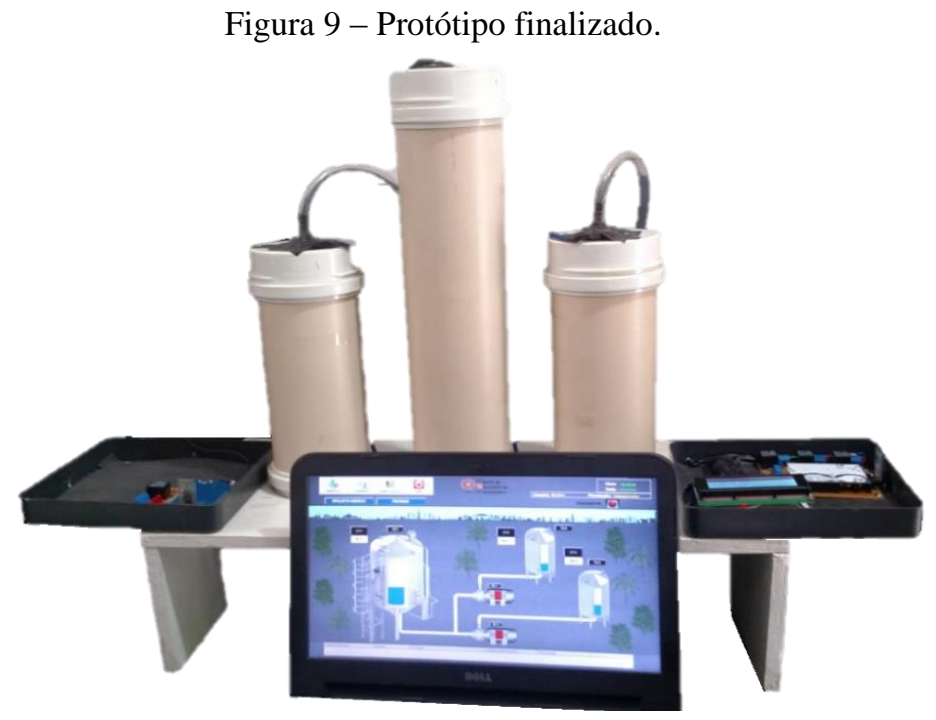

Fonte: Autoria Própria.

\section{CONCLUSÃO}

O presente artigo compreende o desenvolvimento de um protótipo em escala reduzida de uma planta automatizada e supervisionada de um sistema de distribuição hídrico. A escolha pelo sistema hídrico se explica pela intenção do desenvolvimento de um protótipo que aproxime o aluno do ambiente industrial, o que se identifica na utilização, por exemplo, do supervisório Elipse E3, além da busca pela simulação de um processo que seja altamente empregado no setor industrial, assim como é o gerenciamento de recursos hídricos.

Destaca-se que o trabalho apresentado foi uma ação multi e interdisciplinar com foco principal vinculado à: sistemas embarcados; eletrônica; automação; instrumentação; lógica e programação; interface homem máquina.

Através do emprego da automação, descrito no presente trabalho foi possível atender exigências mais rigorosas de precisão e identificação de vazamentos e fraudes presentes nas ETA's, tudo objetivando melhorar o monitoramento e controle das variáveis associadas à distribuição de água.

Por fim, sugere-se como possibilidade para a realização de trabalhos futuros a implementação de outra tecnologia de comunicação, em alternativa ao sistema bluetooth, cujo emprego seja mais adequado para uma aplicação real, na qual questões como alcance são imprescindíveis. Vale ressaltar a importância de projetos e ações como esta, cujo conhecimento aprendido em sala de aula é aplicado de forma prática, além de se desenvolver um conhecimento extracurricular.

\section{Agradecimentos}

Os autores agradecem ao IFMG - Campus Formiga, em especial ao GSE - Grupo de Soluções em Engenharia, pela interação e colaboração no desenvolvimento do presente trabalho. 


\title{
REFERÊNCIAS
}

ASSEMBLEIA DA REPÚBLICA. Decreto Regulamentar N. 23/95 (1995) Aprova o Regulamento Geral dos Sistemas Públicos e Prediais de Distribuição de Água e de Drenagem de Águas Residuais, Diário da República n. ${ }^{\circ}$ 194/ 95,1-B Série.

COMER, Douglas. Interligação de Redes com TCP/IP-: Princípios, Protocolos e Arquitetura. Elsevier Brasil, 2016.

DOS SANTOS, Alexsandro Silveira; MACHADO, Everton; DE SOUZA, João Artur. Construção de uma bancada didática de baixo custo para ensino de sistemas de controle/Construction of a low cost didactic bench for teaching control systems. Brazilian Applied Science Review, v. 3, n. 1, p. 133-144, 2018.

GERONIMO, Alinne. Aprimoramento da bancada didática portátil de refrigeração. 2017. Trabalho de Conclusão de Curso. Universidade Tecnológica Federal do Paraná.

SINIS, Secretaria Nacional De Saneamento Ambiental. Sistema Nacional de Informações sobre Saneamento: diagnóstico dos serviços de água e esgotos - 2010. Brasília, DF: Ministério das Cidades, 2017. Disponível em: http://www.snis.gov.br. Acesso em: 25 jul. 2020.

UNITED NATIONS. Transforming our world: the 2030 Agenda for Sustainable Development A/RES/70/1. New York: ONU, 2016.

\section{DEVELOPMENT OF AN AUTOMATED WATER SUPPLY SYSTEM FOR MULTIDISCIPLINARY DIDACTIC PURPOSES}

\begin{abstract}
The search for auxiliary teaching systems has become important for the development of students, especially when these methods are related or imply the small scale reproduction of an industrial process, all to ensure that the student can put into practice the content learned in subjects, contributing to their access to the job market that is becoming increasingly demanding. Thus, a process with different applications, in addition to its high employability in the industrial sector, is the management of water resources, a process to which several sensing and performance techniques are related, which highlights the importance of their understanding by the students, either by understanding the process itself or even by knowing how to acquire field signals, process those signals, store and dispose of them at a high level interface (SCADA). Thus, this article describes the development of a prototype of the distribution system of a water treatment plant (ETA) on a small scale, whose differential is the use of interdisciplinarity for its development, with emphasis, for example, on areas such as embedded systems, automation, instrumentation, logic and programming, with special attention to the supervisory system. All this in order to present to students of the Federal Institute of Education, Science and Technology of Minas Gerais, Campus Formiga, a challenge similar to what can be found in professional practice as engineers, emphasizing the importance of practicing learned theoretical concepts.
\end{abstract}

Keywords: Interdisciplinarity. Automation. Embedded s 